\title{
Development of a Mixing Process Using an HB-Type Impeller to Easily Achieve Scale-Up by Maintaining Geometrical Similarity
}

\author{
Yoshihito Kato ${ }^{\mathbb{D}},{ }^{1}$ Haruki Furukawa ${ }^{10},{ }^{1}$ Yasuyuki Ikeda, ${ }^{2}$ Toshikazu Nakanishi, ${ }^{2}$ \\ Tadashi Sano, ${ }^{3}$ and Kenji Tomioka ${ }^{3}$ \\ ${ }^{1}$ Department of Life Science and Applied Chemistry, Nagoya Institute of Technology, Gokiso-cho, Showa-ku, Nagoya-shi, \\ Aichi 466-8555, Japan \\ ${ }^{2}$ Asahi Glassplant Inc., 1978, Takahama, Arao-shi, Kumamoto 864-0025, Japan \\ ${ }^{3}$ Takasago Chemical Engineering Co. Ltd., 3-14-8, Hachimangi, Kawaguchi-shi, Saitama 334-0012, Japan \\ Correspondence should be addressed to Haruki Furukawa; furukawa.haruki@nitech.ac.jp
}

Received 23 April 2018; Revised 18 June 2018; Accepted 26 September 2018; Published 24 October 2018

Academic Editor: Doraiswami Ramkrishna

Copyright ( 92018 Yoshihito Kato et al. This is an open access article distributed under the Creative Commons Attribution License, which permits unrestricted use, distribution, and reproduction in any medium, provided the original work is properly cited.

In recent years, a novel home base-type (HB-type) impeller was developed to be based on observation of the streak line pattern. An HB impeller must be simple, speedy, and stable (3S). When an HB impeller is used on the laboratory beaker scale, the mixing performance of the $\mathrm{HB}$ impeller is better than that of a normal cylindrical stirring bar. In addition, an industrial-scale HB impeller has been constructed based on the observation of the streak line and isolated mixing regions in the vessel. The present authors believe that scale-up of the mixing process is very easy because the geometrical shape of the impeller can be kept consistent when scaling up from the laboratory scale to the industrial scale.

\section{Introduction}

Although numerous engineering data and mixing processes have been reported, successful scale-up of the mixing process has been very difficult because the design and operation of mixing process involve numerous parameters.

There are a number of basic scale-up rules for mixing processes, including constant power consumption per unit volume, constant impeller tip speed, constant heat transfer coefficient, constant mass transfer volumetric coefficient, and constant just suspension rotational impeller speed. One of the difficult points in scale-up of the mixing process is that when we prioritize a controlling parameter, doing so may adversely impact other parameters. When the Reynolds number is constant for a small-scale or large-scale mixing vessel, the power consumption per unit volume cannot be kept constant. Therefore, if the same physical property of a material is used for industrial production, it is impossible to reproduce the same phenomenon perfectly at a laboratory scale. When scale-up from a laboratory process to an industrial process is carried out, the geometrical similarity generally cannot be maintained. For example, when a cylindrical magnetic stirring bar is used for small-scale processes in the laboratory, a mixing vessel with a paddle impeller may be used for the corresponding large-scale industrial process. In addition, a number of mixing impellers, such as paddle, turbine, propeller, anchor, helical ribbon, and a number of novel large-paddle impellers, have been developed.

In recent years, several large-paddle impellers, including Maxblend (MB), Fullzone (FZ), Supermix MR205 (MR205), Sammeler (SM), Hi-F mixer (HiF), and Bendleaf (BL), were developed by Japanese companies [1-3]. These impellers are very useful under a wide range of Reynolds numbers.

Inoue et al. [4] suggested a streak line theory to estimate the performance of the mixing vessel and concluded that the streak line pattern was an indication of the mixing. In the previous papers, authors found the important mixing performance of various large-paddle impellers using the streak line visualization method proposed by Inoue et al. In addition, the liquid height was found to be a very important factor when the MB and FZ impellers were used in the laminar region. 
The present authors developed a new home base-type (HB-type) impeller, a designation based on the shape of the home plate used in baseball, used under a wide range of Reynolds numbers, as shown in Figure 1 [5]. The HB-type impeller must be simple, speedy, and stable (3S). (1) Simple: since the impeller geometry is very simple, washing the impeller is easy and the production cost is low. The HB impeller is suitable for small-lot production of numerous products. (2) Speedy: the mixing time is very short. (3) Stable: the streak line pattern is stable under a wide range of Reynolds numbers. Even if the liquid height has changed, the HB impeller has demonstrated stable, good mixing performance.

The present authors developed a mixing process using an HB-type impeller for a laboratory scale, a pilot scale, and an industrial scale. In the present paper, authors demonstrate the mixing performance of the HB impeller and the scale-up system of the mixing process using the $\mathrm{HB}$ impeller.

\section{Experimental}

Two types of mixing vessels without baffles were used for the pilot scale vessel. When the streak line was observed, the vessel diameter was $0.150 \mathrm{~m}$, and the impeller was made with an acrylic resin. When the mixing process was observed, the vessel diameter was $0.185 \mathrm{~m}$, and the impellers used in flat and dished bottoms were made with stainless steel. The mixing fluid was a starch syrup solution, which was filled to a height equal to the vessel diameter $(H=D)$. The power consumption was measured by the shaft torque measurement method using a torque meter (ST-3000, SATAKE Ltd.). The streak lines were visualized by uranine, and the mixing process was visualized by an iodine decoloration reaction.

The experimental visualization of streak line was conducted by uranine solution and a planar laser light. $0.025 \mathrm{~g}$ of uranine powder was dissolved into $100 \mathrm{ml}$ of the starch syrup solution to prepare the same viscosity solution as the mixing fluid. The uranine solution was injected at an impeller tip through the impeller hollow shaft. The uranine solution was vertically illuminated by the planar laser light to observe streak line.

The decoloration experiment was based on the oxidation-reduction reaction. Sodium thiosulfate and iodine were adopted as oxidation and reduction agent, respectively. Sodium thiosulfate and iodine were dissolved into the starch syrup solution to obtain the same viscosity as the mixing fluid. Concentrations of sodium thiosulfate solution and iodine solution were $0.5 \mathrm{~mol} / \mathrm{l}$. The iodine solution was added to the mixing fluid, and then the thiosulfate solution was added to the mixing fluid at the liquid surface. The ratio of the iodine solution and the thiosulfate solution was 1 to 1.4. This ratio was allowed to judge the mixing time easily [5]. So, added volume of the iodine solution and the thiosulfate solution were $1 \mathrm{ml}$ and $2.8 \mathrm{ml}$, respectively. These experimental methods are the same as previous papers [6].

A $500 \mathrm{ml}$ glass beaker was used for the small-scale experiment. A small-scale HB impeller made from a PTFE board was installed on a cylindrical stirring bar, as shown in Figure 2. The vessel diameter $D$, the impeller diameter $d$, and the impeller height $b$ are $0.085 \mathrm{~m}, 0.05 \mathrm{~m}$, and $0.045 \mathrm{~m}$, respectively. The attachment and removal of a normal

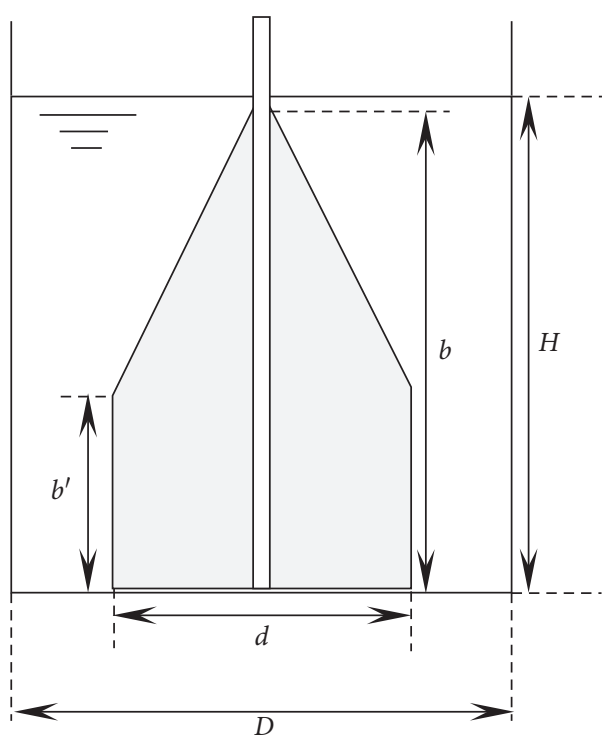

FIGURE 1: Schematic diagram of the HB-type impeller.

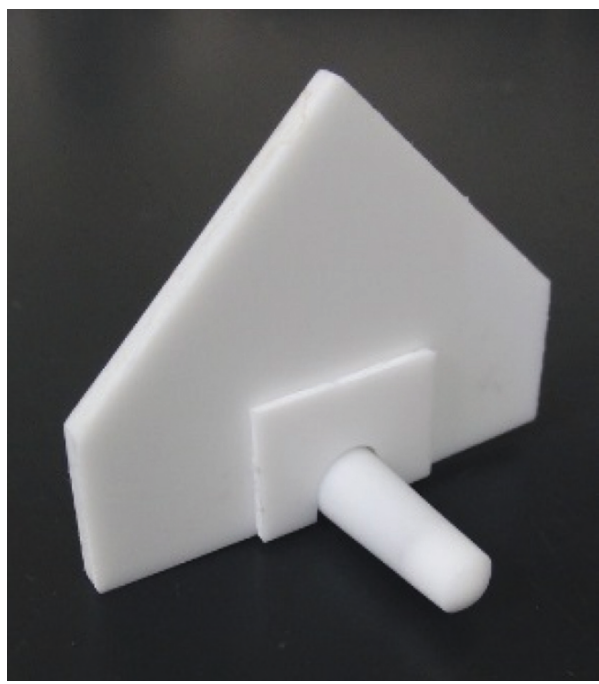

Figure 2: HB-type stirring bar.

cylindrical stirring bar of an HB impeller is very easy, because the stirring bar is simply forced into a hole in the lower part of the HB impeller.

\section{Results and Discussion}

3.1. Mixing Performance of the HB Impeller for the Pilot Scale. First, Figures 3 and 4 show typical streak line patterns of a two-blade paddle impeller. Although the streak line pattern was different at different Reynolds numbers, the same pattern was observed at the same Reynolds number, even if the impeller rotational speed and the vessel size were changed. A pair of isolated mixing regions (IMRs) were observed in the laminar flow region at $\mathrm{Re}=10$ and 70 .

Figure 5 shows a time series of the typical streak line patterns of the HB impeller. The streak line pattern spreads 


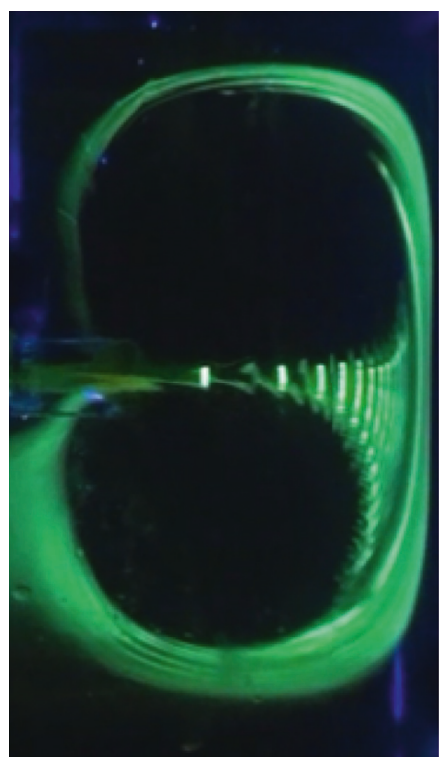

(a)

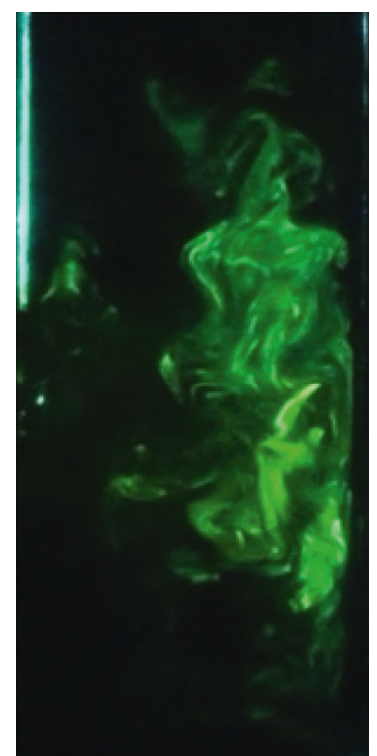

(b)

Figure 3: Streak line patterns of a paddle impeller at $\operatorname{Re}=10$ (a) and $\operatorname{Re}=2,600$ (b).

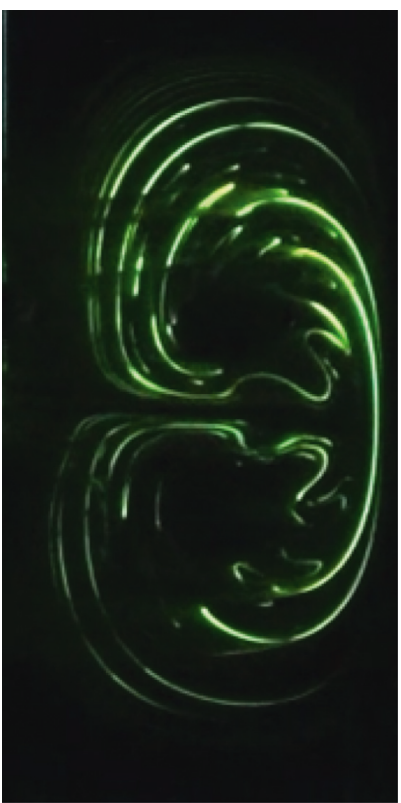

(a)

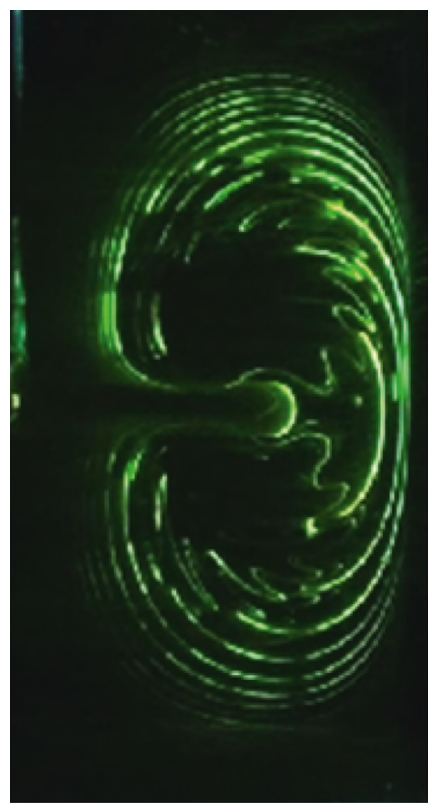

(b)

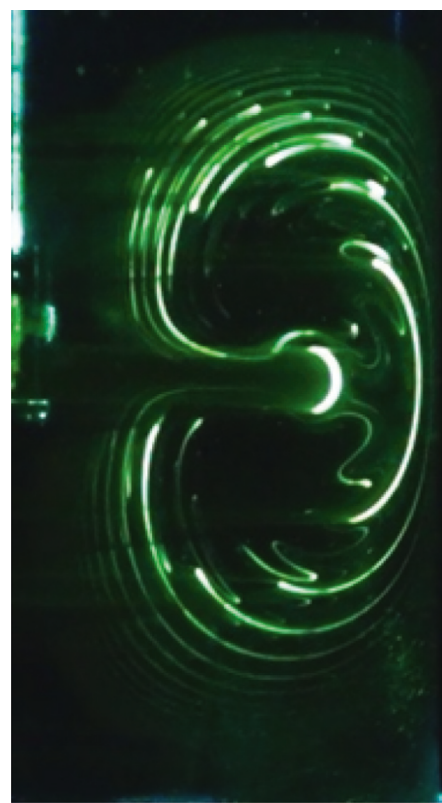

(c)

FIGURE 4: Streak line patterns of a paddle impeller at $\operatorname{Re}=70$. (a) $n=25 \mathrm{rpm}$; (b) $n=50 \mathrm{rpm}$; (c) diameter $=1.3 D$.

speedily throughout the vessel after a few rotations of the impeller, whereas no IMR was observed.

Figures 6 and 7 show time series of the mixing process of the HB impeller. An IMR shaped like a doughnut was not observed in the laminar region, and no cylindrical rotation zone (CRZ) was observed in the turbulent region in vessels with either a flat or dished bottom. The most important consideration in the operation of the HB impeller is that the installment of baffles is not necessary under a wide range of Reynolds numbers. The optimum ratio of the impeller diameter to the vessel diameter $(d / D)$ was found to be 0.6 to
0.7. This ratio is the same as that of the other two-blade wide paddle impellers considered herein. The power number of the $\mathrm{HB}$ impeller was estimated (1) in the laminar region, in which the correlation of MB, FZ, and MR205 can be used and (2) in the turbulent region, in which the correlation of the paddle impeller can be used when impeller height is considered to be $b^{\prime}$ (see Figure 1) [7].

3.2. Mixing Performance of the HB Impeller for the Laboratory Scale. Figures 8 and 9 show mixing processes using a normal magnetic cylindrical stirring bar and the $\mathrm{HB}$ impeller in 


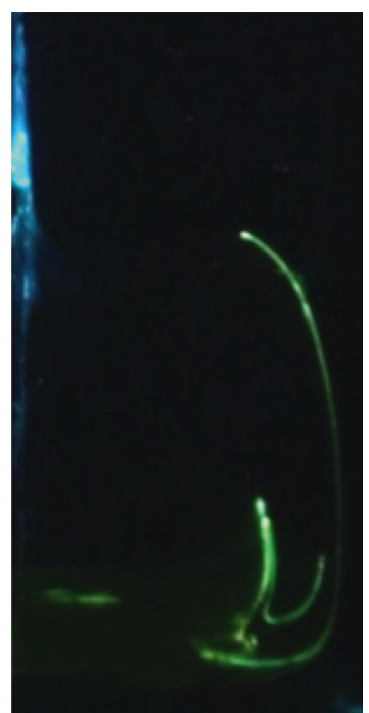

(a)

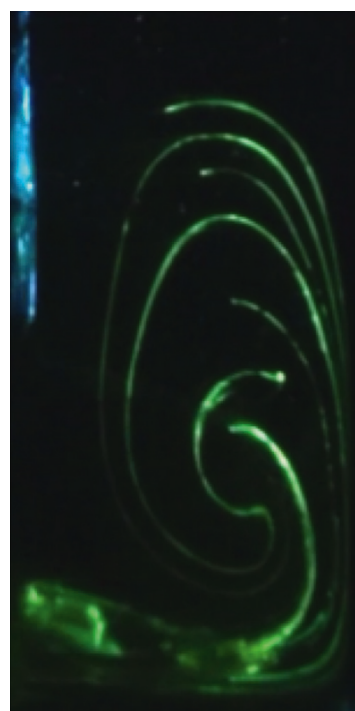

(b)

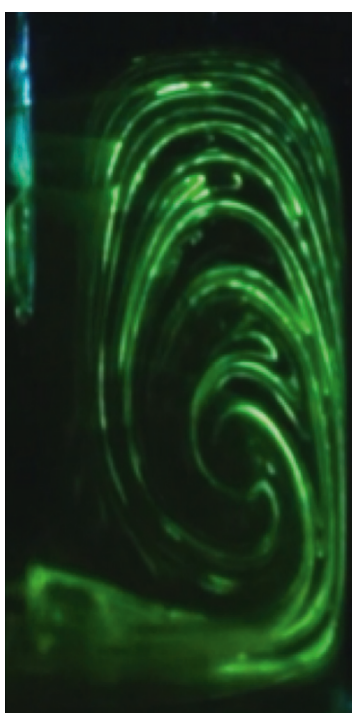

(c)

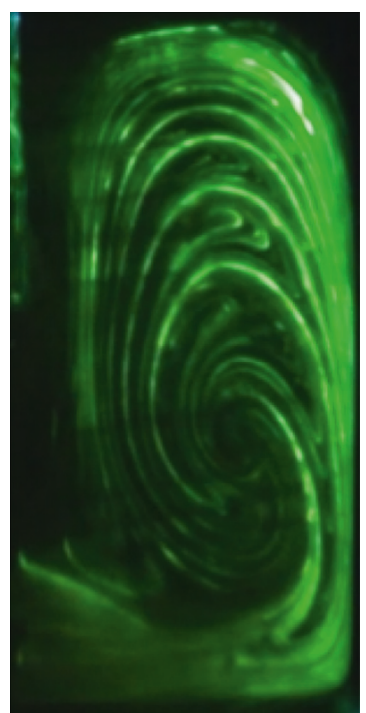

(d)

FIGURE 5: Streak lines generated by the HB-type impeller. (a) Rotation $=4$; $(\mathrm{b})$ rotation $=6$; $(\mathrm{c})$ rotation $=10$; $(\mathrm{d})$ rotation $=14$.

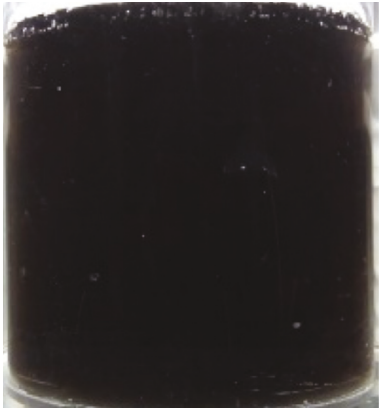

(a)

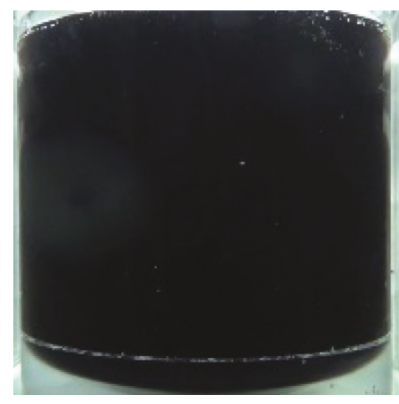

(e)

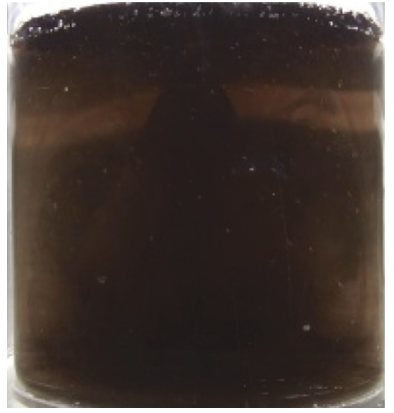

(b)

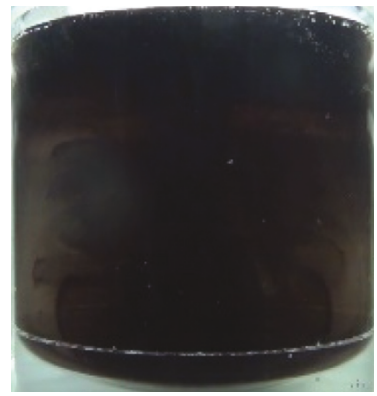

(f)

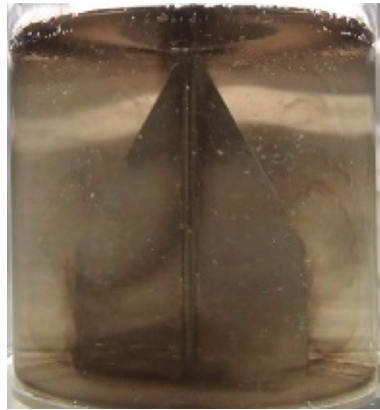

(c)

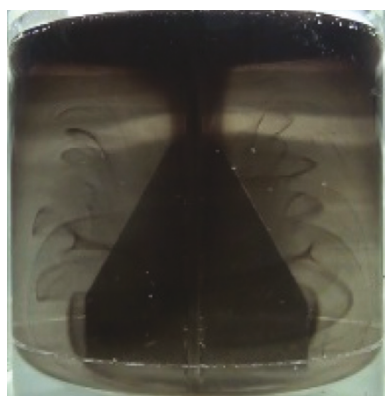

(g)

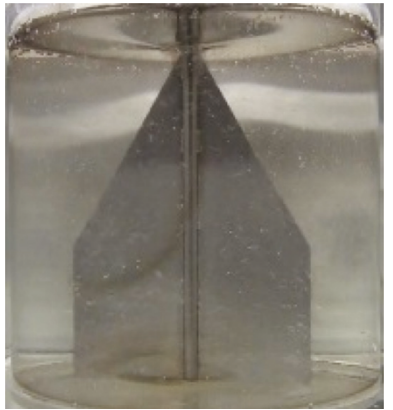

(d)

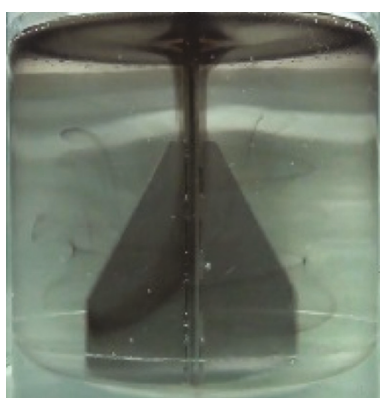

(h)

Figure 6: Mixing process of HB impeller at Re $=100$, flat bottom ((a) $0 \mathrm{~s}$, (b) $10 \mathrm{~s}$, (c) $15 \mathrm{~s}$, and (d) $30 \mathrm{~s}$ ) and dished bottom ((e) $0 \mathrm{~s}$, (f) $10 \mathrm{~s}$, (g) $15 \mathrm{~s}$, and (h) $30 \mathrm{~s})\left(\mu=0.29 \mathrm{~Pa} \cdot \mathrm{s}, \rho=1,327 \mathrm{~kg} / \mathrm{m}^{3}\right.$, and $\left.n=100 \mathrm{rpm}\right)$.

a $500 \mathrm{ml}$ beaker, respectively. The fluid viscosity was $60 \mathrm{mPa} \cdot \mathrm{s}$ in the cylindrical stirred bar, whereas the HBtype stirring bar (Asahi Glassplant Inc.) achieved complete mixing in the beaker, as shown in Figure 9. Figures 10 and 11 show the mixing processes of the normal cylindrical stirring bar and the HB impeller in a $500 \mathrm{ml}$ beaker filled with deionized water in the turbulent region. A CRZ was observed in the vessel stirred with a normal bar, as shown in Figure 10. However, the CRZ was not observed in the vessel mixied with HB-type bar, and complete mixing was achieved quickly at a lower rotational speed. It was difficult to measure the power consumption of the $\mathrm{HB}$ impeller for the laboratory scale because it was used with magnetic stirrer. However, the power consumption was able to be estimated by the correlation of the $\mathrm{HB}$ impeller [7]. 


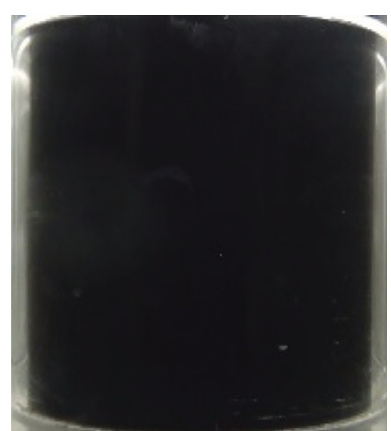

(a)

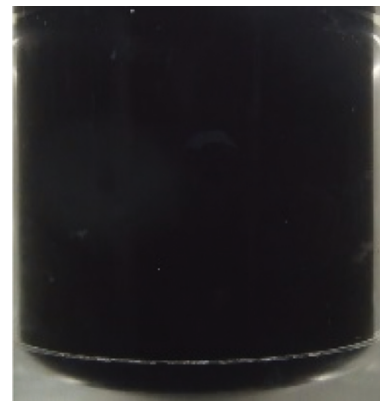

(e)

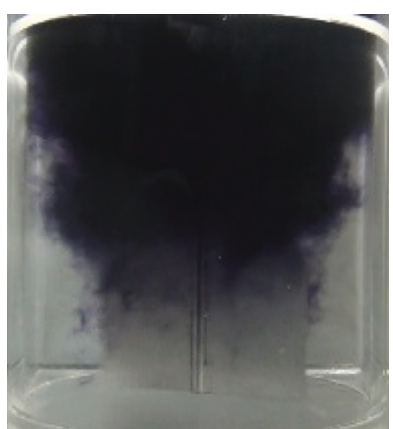

(b)

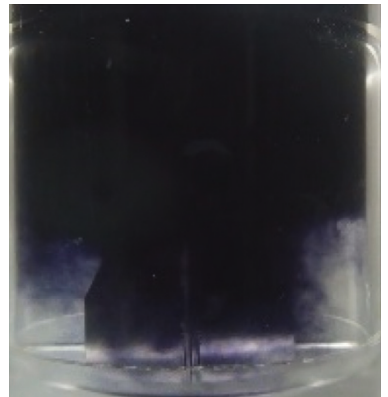

(f)

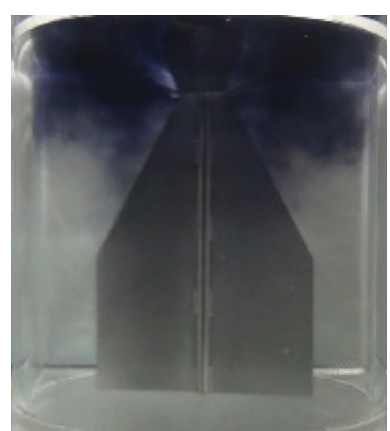

(c)

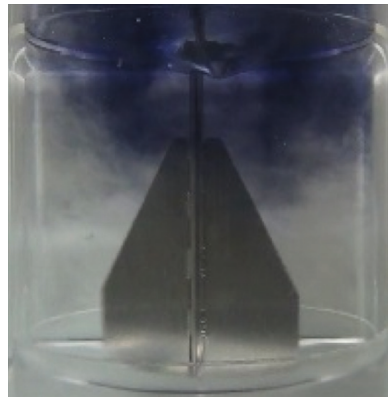

(g)

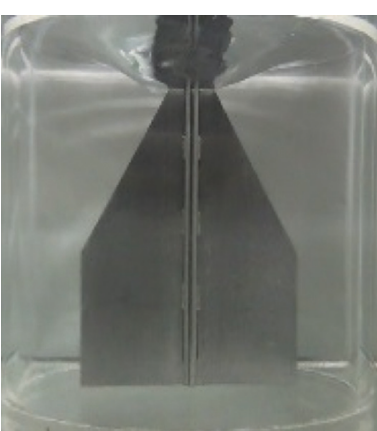

(d)

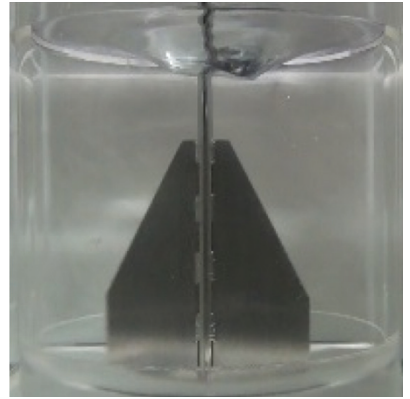

(h)

FIGURE 7: Mixing process at Re $=23,000$ of $\mathrm{HB}$ impellers with a flat bottom ((a) $0 \mathrm{~s}$, (b) $5 \mathrm{~s}$, (c) $8 \mathrm{~s}$, and (d) $10 \mathrm{~s})$ and a dished bottom ((e) $0 \mathrm{~s}$, (f) $5 \mathrm{~s},(\mathrm{~g}) 10 \mathrm{~s}$, and (h) $12 \mathrm{~s})\left(\mu=1 \mathrm{mPa} \cdot \mathrm{s}, \rho=1,000 \mathrm{~kg} / \mathrm{m}^{3}\right.$, and $\left.n=100 \mathrm{rpm}\right)$.

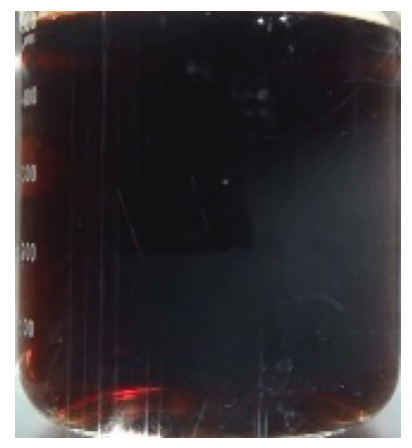

(a)

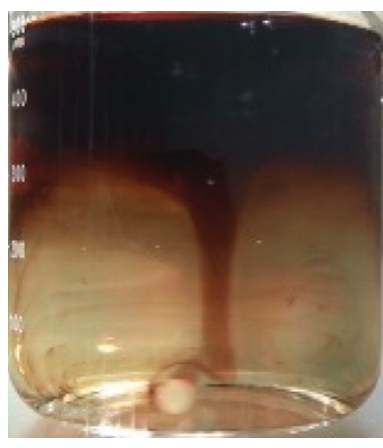

(b)

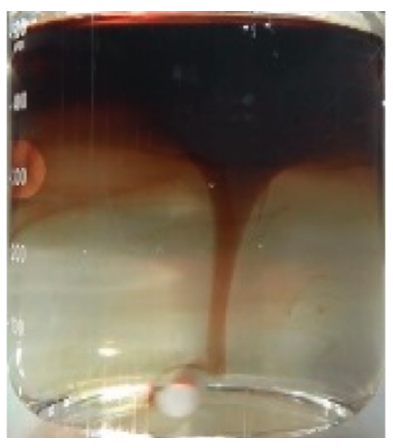

(c)

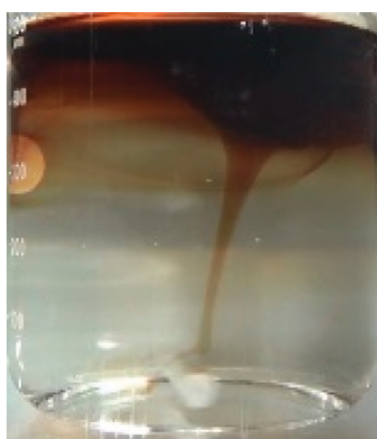

(d)

FIgURE 8: Mixing using a normal bar at $n=100 \mathrm{rpm}$. (a) $0 \mathrm{~s}$, (b) $60 \mathrm{~s}$, (c) $120 \mathrm{~s}$, and (d) $300 \mathrm{~s}$.

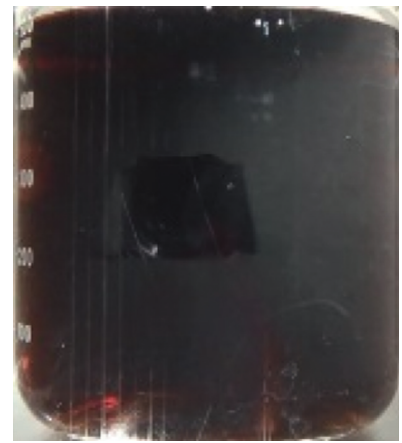

(a)

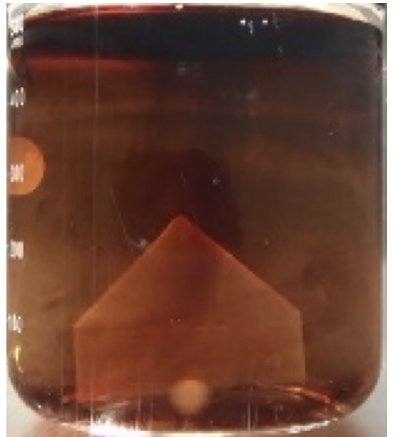

(b)

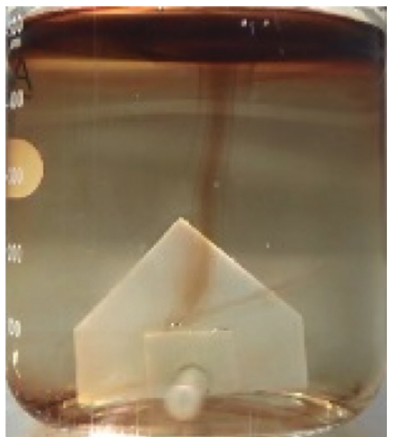

(c)

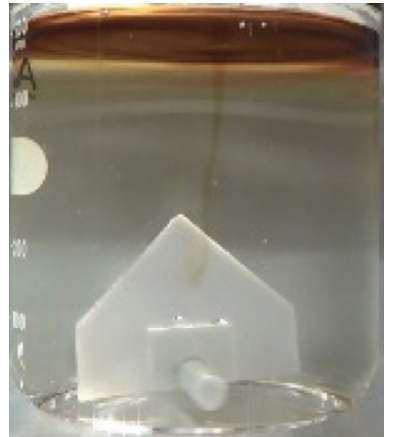

(d)

Figure 9: Mixing using an HB-type bar at $n=100 \mathrm{rpm}(\operatorname{Re}=80)$. (a) $0 \mathrm{~s}$, (b) $10 \mathrm{~s}$, (c) $20 \mathrm{~s}$, and (d) $60 \mathrm{~s}$. 


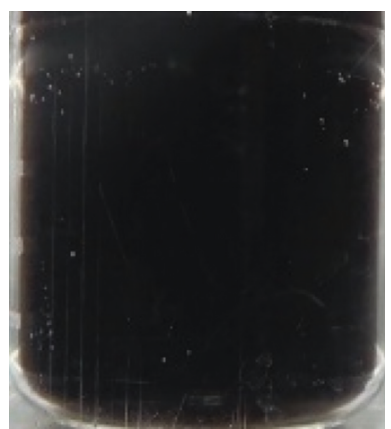

(a)

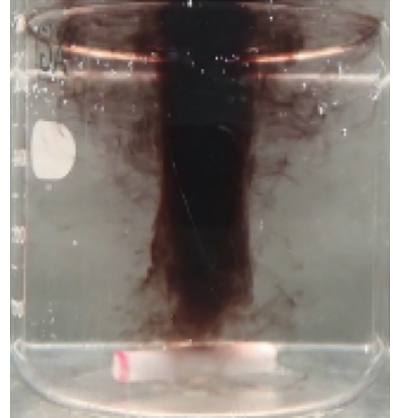

(b)

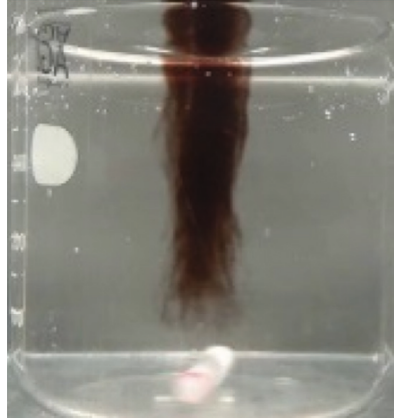

(c)

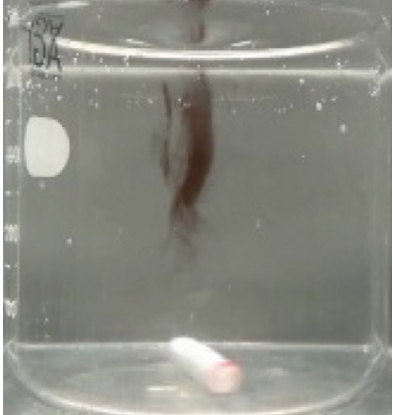

(d)

Figure 10: Mixing using a normal bar at $n=200 \mathrm{rpm}$. (a) $0 \mathrm{~s}$, (b) $5 \mathrm{~s}$, (c) $20 \mathrm{~s}$, and (d) $40 \mathrm{~s}$.

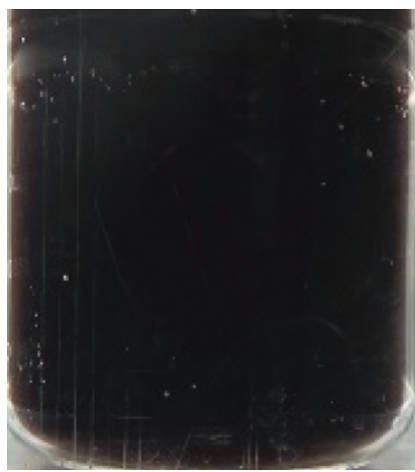

(a)

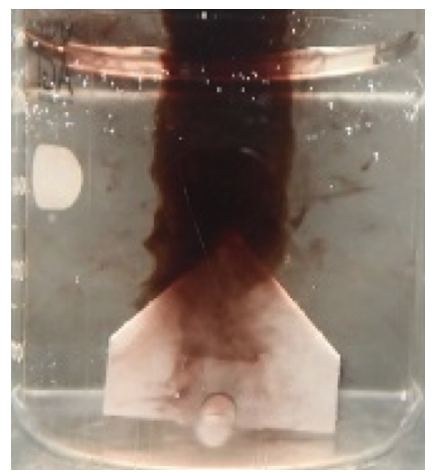

(b)

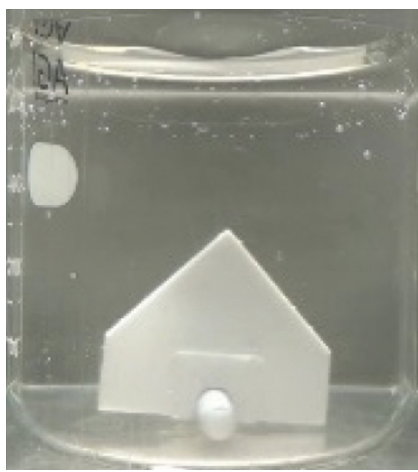

(c)

Figure 11: Mixing using an HB-type bar at $n=100 \mathrm{rpm}(\operatorname{Re}=4,200)$. (a) $0 \mathrm{~s}$, (b) $5 \mathrm{~s}$, and (c) $13 \mathrm{~s}$.

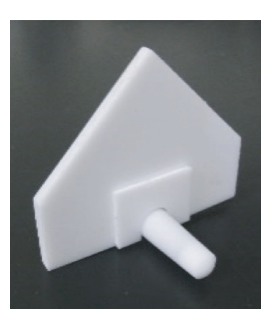

(a)

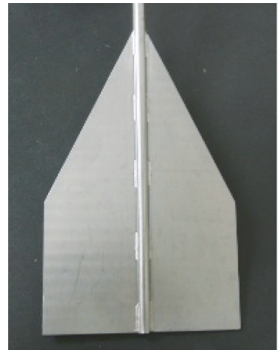

(b)

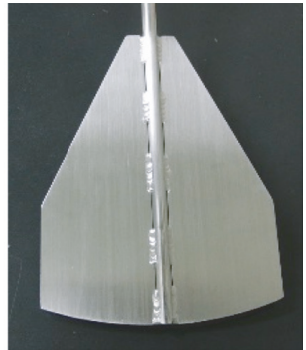

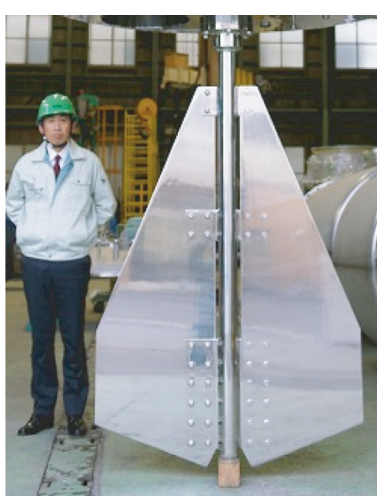

(c)

Figure 12: Scale-up system of the HB impeller. (a) Laboratory scale $(500 \mathrm{~mL})$, (b) pilot scale (5 L), and (c) Industrial scale $\left(4 \mathrm{~m}^{3}\right)$.

As described above, the HB-type impeller can be used in a small-scale vessel. On the other hand, other two-blade wide paddle impellers developed by Japanese companies cannot be used because their geometrical shape is very complicated. In addition, the geometrical shapes of these other impellers are complicated, which makes them difficult to wash, and they are not suitable for laboratory use.

Generally, in organic synthesis, polymerization, inorganic reactions, and dispersion of a catalyst, a normal cylindrical stirring bar is used. However, the proposed HB impeller will improve the efficiency of such synthetic reactions in the laminar region. As shown in Figure 8, complete mixing cannot be achieved using the normal.

3.3. Scale-Up of the HB Impeller to Industrial Scale. An industrial-scale HB impeller $(D=1.7 \mathrm{~m})$ has been developed by Takasago Chemical Engineering Co. Ltd. based on the above-described considerations, as shown in Figure 12 . 


\section{Conclusions}

Scale-up of the novel HB-type impeller became very easy because the geometrical shape of the impeller can be kept consistent from an experiment at laboratory scale to production at an industrial scale. In addition, since geometrical similarity is to be maintained, the proposed HB-type impeller addresses one of the difficulties in scale-up to industrial-scale production.

\section{Nomenclature}

$b$ : Height of the impeller blade $(\mathrm{m})$

$b^{\prime}$ : Height of the discharge part of the impeller blade (m)

$D$ : Vessel diameter $(\mathrm{m})$

$d: \quad$ Impeller diameter $(\mathrm{m})$

$H$ : Liquid depth (m)

$n$ : Impeller rotational speed $\left(\mathrm{s}^{-1}\right)$

Re: Impeller Reynolds number $\left(=n d^{2} \rho / \mu\right)(-)$

$\mu$ : Liquid viscosity (Pa.s)

$\rho$ : Liquid density $\left(\mathrm{kg} \cdot \mathrm{m}^{-3}\right)$

\section{Data Availability}

The experimental data used to support the findings of this study are included within the article.

\section{Conflicts of Interest}

The authors declare that they have no conflicts of interest.

\section{Acknowledgments}

The authors would like to thank Mr. Masashi Hiramatsu, Mr. Shota Otani, Mr. Keisuke Suzuki, and Mr. Yutaka Hiragushi for their support in conducting the experiment. The present study was supported by Nagoya Institute of Technology, Asahi Glassplant Inc., and Takasago Chemical Engineering Co. Ltd.

\section{References}

[1] M. Aida and A. Shono, "Estimation of power consumption in gas-liquid stirred vessels with various types of impellers," Kagaku Kogaku Ronbunshu, vol. 40, no. 5, pp. 366-371, 2014.

[2] N. Dohi, T. Takahashi, K. Minekawa, and Y. Kawase, "Gasliquid mass transfer characteristics of large-scale impellers: empirical correlations of gas holdups and volumetric mass transfer coefficients in stirred tanks," Chemical Engineering Communications, vol. 193, no. 6, pp. 689-701, 2006.

[3] R. Yatomi, K. Takenaka, K. Takahashi, and P. A. Tanguy, "Mass transfer characteristics by surface aeration of large paddle impeller: application to a polymerization reactor with liquid level change," Journal of Chemical Engineering of Japan, vol. 40, no. 5, pp. 393-397, 2007.

[4] Y. Inoue, D. Takaoka, B. Okada, K. Natami, S. Hashimoto, and Y. Hirata, "Analysis of fluid mixing in an agitated vessel based on a streakline," Kagaku Kogaku Ronbunshu, vol. 35, no. 3, pp. 265-273, 2009.

[5] Y. Kato, M. Hiramatsu, S. Ohtani, M. Yoshida, and K. Shiobara, "Development of new large paddle (HB type) impeller based on streak line observation,” Kagaku Kogaku Ronbunshu, vol. 41, no. 1, pp. 16-20, 2015.

[6] K. Takahashi, Y. Takahata, T. Yokota, and H. Konno, "Mixing of two miscible highly viscous Newtonian liquids in a helical ribbon agitator," Journal of Chemical Engineering of Japan, vol. 18, no. 2, pp. 159-162, 1985.

[7] Y. Kato, S. Ohtani, and H. Furukawa, "Characteristics of power consumption and mixing time of new large paddle (HB type) impeller," Kagaku Kogaku Ronbunshu, vol. 41, no. 5, pp. 276-280, 2018. 


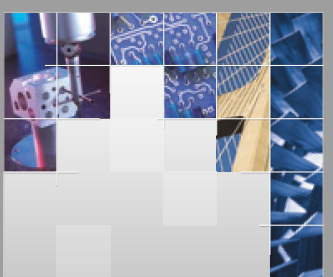

\section{Enfincering}
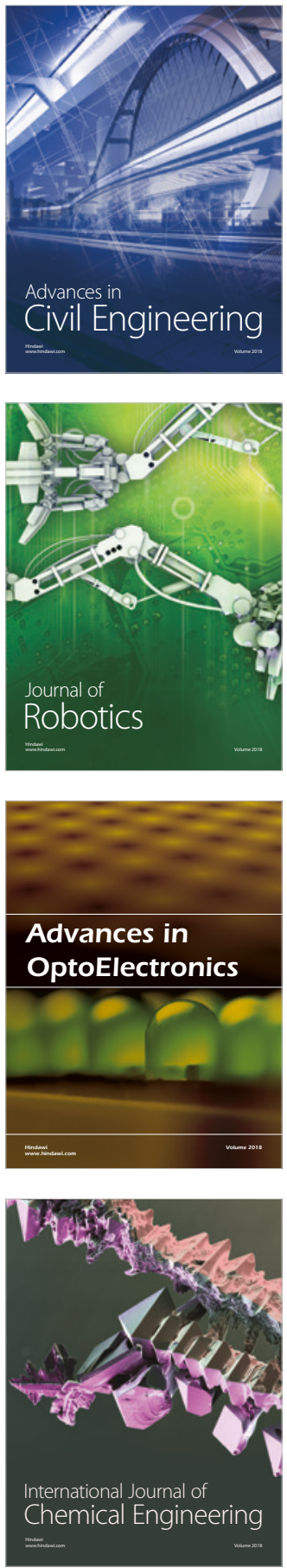

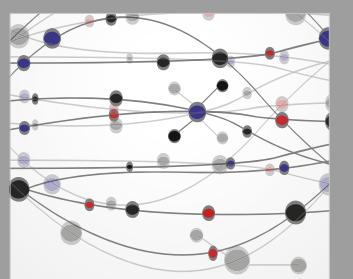

\section{Rotating \\ Machinery}

The Scientific World Journal

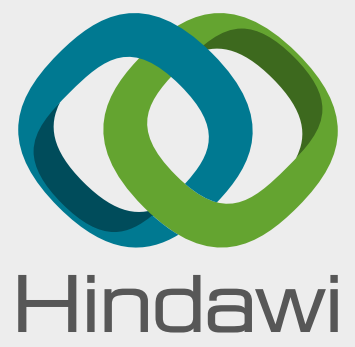

Submit your manuscripts at

www.hindawi.com
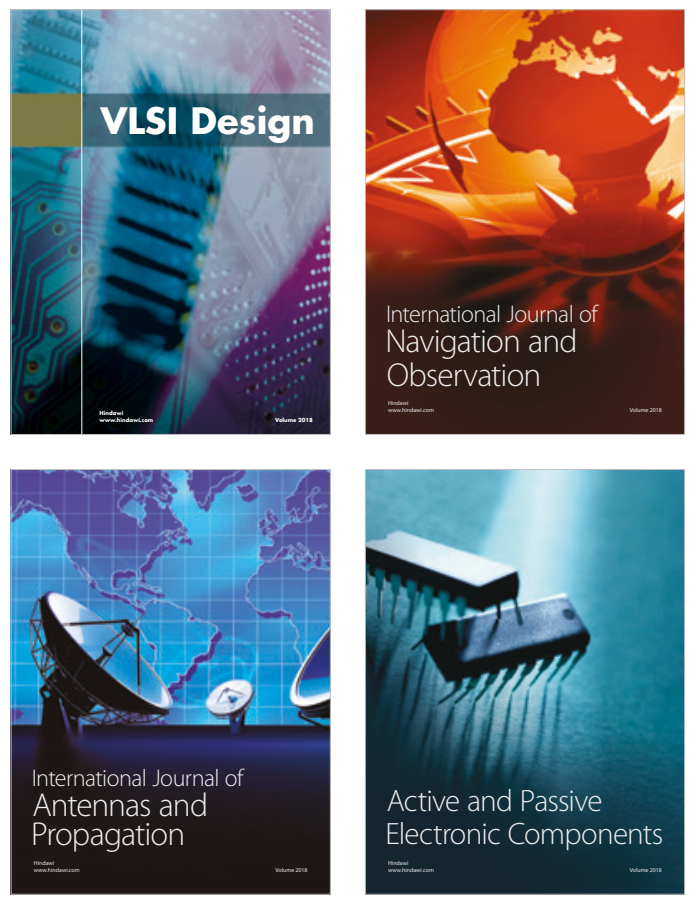
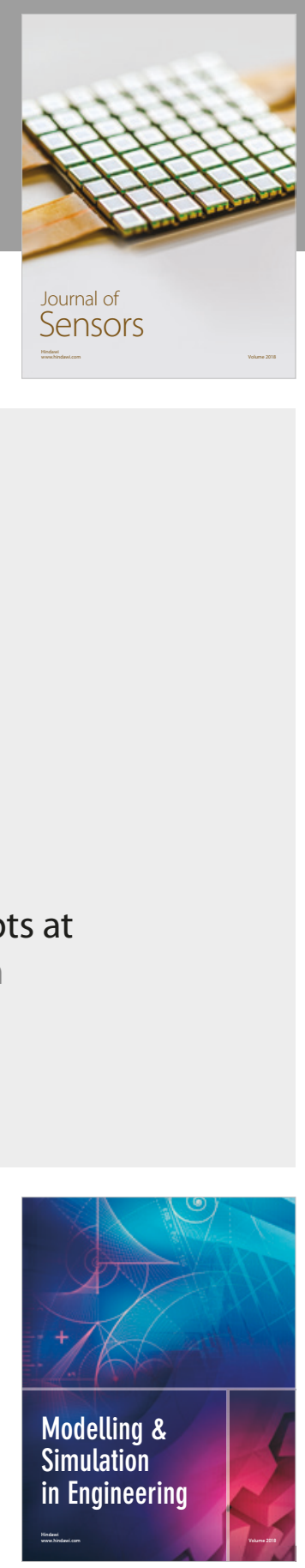

\section{Advances \\ Multimedia}
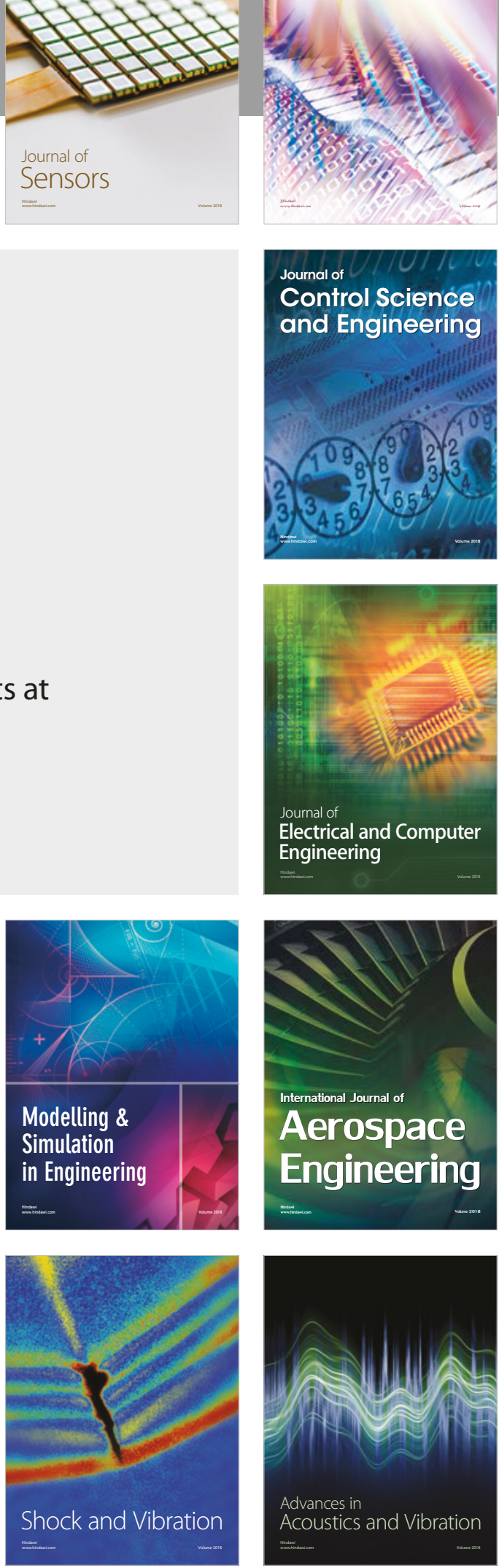